\title{
A Survey of Disaster Medical Education in Osteopathic Medical School Curricula
}

\author{
Steven J. Parrillo, DO, FACOEP-D, FACEP; ${ }^{1}$ Doran Christensen, DO; ${ }^{2}$ Howard S. Teitelbaum, \\ DO, PhD, MPH, FAOCOPM (dist); ${ }^{3}$ Erik S. Glassman, MS, NRP, EMT-T ${ }^{3}$
}

1. Emergency Medicine, Sidney Kimmel Medical College, Thomas Jefferson University; Emergency Medicine, Philadelphia College of Osteopathic Medicine; Einstein Healthcare Network, Philadelphia, Pennsylvania USA

2. Radiation Emergency Assistance Center/ Training Site (REAC/TS), Oak Ridge Institute for Science and Education (ORISE), Oak Ridge, Tennessee USA

3. Department of Preventive and Community Medicine, Lincoln Memorial UniversityDeBusk College of Osteopathic Medicine, Harrogate, Tennessee USA

\section{Correspondence: \\ Steven J. Parrillo, DO, FACOEP-D \\ Einstein Healthcare Network \\ Philadelphia, Pennsylvania USA 19141 \\ E-mail: parrills@einstein.edu}

Conflicts of interest: None of the authors has a financial stake or a conflict of interest in the survey's production or the interpretation of the data it generated.

Keywords: disaster; medial education; osteopathic medical schools

Received: June 4, 2016

Accepted: July 1, 2016

Online publication: September 19, 2016

doi:10.1017/S1049023X16000868
Parrillo SJ, Christensen D, Teitelbaum HS, Glassman ES. A survey of disaster medical education in osteopathic medical school curricula. Prehosp Disaster Med. 2016; 31(6):581-582.

From Hurricane Katrina (2005; Louisiana/Mississippi USA) to "Superstorm" Sandy (2012; New York/New Jersey USA), large-scale disasters have had tremendous impact on the United States in recent years. While there are many definitions of a disaster, the Institute of Medicine (IOM; Washington, DC USA) defines one as "an event that creates a significant, short-term spike in the demand for emergency care services requiring extraordinary measures." Several authors have noted that Americans are ill-prepared to deal with such events. ${ }^{1-3}$ Several reports have documented that many cities and states recognize their inability to respond adequately for a variety of reasons. ${ }^{3,4}$ Smith et al. published a study that addressed disaster curricula in allopathic medical schools. Twenty-nine of 115 (25.2\%) allopathic schools responded to that survey. Only 31\% included disaster medicine in their core curriculum. ${ }^{5}$

In 2003, the American Association of Medical Colleges (Washington, DC USA) called for disaster medicine and public health preparedness to be introduced into the medical school curriculum. That report did so by charging schools to integrate weapons of mass destruction education into their existing curriculum. ${ }^{6}$ To provide a broader, all-hazards knowledge base, several authors have advocated for core competencies to be taught in health professions. ${ }^{7,8}$

Kaiser et al. ${ }^{9}$ surveyed allopathic and osteopathic medical students in 2009 to determine their perspectives on disaster preparedness and their willingness to serve in some capacity in each of three scenarios: a natural disaster, a pandemic influenza, and a radiological dispersion device. A total of 593 responded - a response rate of $60.6 \%$. In all three settings, the overwhelming majority said they would be willing to respond and help regardless of the event's severity.

The study was completed in 2015 when total medical school enrollment was 44,957. The total included 20,343 allopathic and 24,615 osteopathic students. ${ }^{10,11}$ These students represent a potential resource of committed, enthusiastic men and women with the knowledge to help increase the pool of responding health professionals in a setting that includes large numbers of casualties and too few responders. However, little is known about preparation of this large group of future physicians. This study addressed that need.

The authors of this Guest Editorial, all with special interest in and concern for emergency preparedness in the medical community, developed a simple survey regarding current and future disaster medical education at this level. The survey, approved by the Albert Einstein Healthcare Network (Philadelphia, Pennsylvania USA) Institutional Review Board, was distributed electronically to Deans of all osteopathic medical schools in the United States. It was built around core competencies for "informed workers/students" developed by Subarrao et al. ${ }^{7}$ After a few demographic questions, none of which would appear in the final tally of results, curriculum advisors were asked to answer a total of $42 \mathrm{Yes} / \mathrm{No} / \mathrm{Unsure}$ and five Likert-graded Agree/Disagree survey questions. Educational leaders (Deans, Curriculum Directors, and Directors of Medical Education) from 12 schools (32\%) began the survey, but only nine (25\%) completed all questions.

Seven of the nine responders stated that their school offers specific disaster medical training within the curriculum. Three strongly agreed or agreed that disaster medicine is a 
priority in medical education. Seven stated that the curriculum was not competency-based or did not know if it was. Based on response to a series of related questions, seven responders stated that the curriculum at their school includes many aspects of emergency management and preparedness. Five stated that osteopathic students receive adequate clinical training to respond. The strongest areas had to do with clinical competency. Six responders were of the opinion that osteopathic medical students have a role in disaster response. One responder was neutral, but two believed that such students do not have a role. All nine held the opinion that graduate osteopathic physicians have a role in disaster response, but only five held the opinion that graduates are well-equipped to respond.

Three of the nine responders noted that disaster medical education is a priority in their school's curriculum. Six were of the opinion that osteopathic medical students have a role in disaster response. Although the survey did not ask for reasons behind each response, it is possible that curriculum decision makers believe that they must choose to cover topics that students will encounter in clinical rotations and residencies. Disaster medical topics may be considered less relevant. Two responders held the opinion that there is no role for students in disaster response. This may be due to uncertainty that exists in a disaster response situation, or a feeling that disaster medicine topics are covered in other subject areas like microbiology, health care delivery science, family medicine, surgery/trauma, or other fields of study.

The survey demonstrated that very few osteopathic medical schools include formal disaster education in their curricula, though responders felt that there is a need that is met in part by topics covered in other areas of those curricula. All believed that osteopathic graduates have a role in disaster response, though one-half felt that those same graduates aren't well-prepared. Although the response rate to the survey was less than we had hoped, it is consistent with the efforts of a previous allopathic medical school survey. ${ }^{5}$ There are several possibilities for the low response rate, including the pressures of time and "information overload." We believe, however, that the responses point out areas where medical schools (allopathic and osteopathic) could modify curriculum in a meaningful and practical way.

Curriculum designers should consider how to include disaster medical topics within a framework that is realistic in the current world environment. In so doing, students would be better prepared for some role in disaster response, either while still students or after graduation. Subbarao et al. list "domains," including preparation and

\section{References}

1. Maurer DC. National Preparedness - FEMA has made progress, but additional steps are needed to improve grant management and assess capabilities. http://www.gao.gov/ products/GAO-13-637T. Published June 25, 2013. Accessed December 15, 2014.

2. Federal Signal Corporation. Revealing Americans' awareness and preparedness surrounding emergency situations. 2012 Third Annual Safety Survey. http:// emcomm.federalsignal.com/sites/emcc/files/federal_signal_public_safety_survey.pdf. Accessed December 15, 2014.

3. Redlener I. Americans at Risk: Why We Are Not Prepared for Mega-disasters and What We Can Do Now. http://ncdp.columbia.edu/library/publications/americans-at-riskwhy-we-are-not-prepared-for-megadisasters-and-what-we-can-do-now/. Accessed January 6, 2015.

4. Boyd WJ. Measuring the effectiveness of disaster preparedness training in the city of Bellingham, Washington. https:/www.usfa.fema.gov/pdf/efop/efo30596.pdf. Accessed December 31, 2015.

5. Smith J, Levy MJ, Hsu EB, Lee Levy J. Disaster curricula in medical education: pilot survey. Prehosp Disaster Med. 2012;27(5):492-494.

6. Association of American Medical Colleges. Training Future Physicians about Weapons of Mass Destruction: Report of the Expert Panel on Bioterrorism Education for Medical Students. Washington, DC USA: Association of American Medical Colleges; 2003. planning; detection and communication; incident management and support systems; safety and security; clinical/public health assessment and intervention; contingency, continuity, and recovery; and public health law and ethics. The competencies within the purview of each group are refinements of the seven domains that apply to all health professionals. Markensan et al. ${ }^{8}$ described a process and a list of core competencies for teaching emergency preparedness to students in health care professions. These core competencies included emergency management and preparedness, terrorism and public health emergency preparedness, public health surveillance and response systems, and patient care for disasters, terrorism, and public health emergencies. The authors list subject areas within each category. They also point out that health care workers are part of the second largest workforce in the US, second only to the US military. As such, disaster education would help prepare a large number of potential responders.

We believe that there is much the osteopathic profession can do to address the shortcomings identified in our survey. Recognizing that curriculum decision makers must determine what their students must learn, we believe that a standardized course of study would benefit students and prepare them for the possibility of assisting in an actual disaster. A working group representing a variety of disciplines and stakeholders could develop a suggested disaster medical education curriculum to be included in current ones. Once that work is complete, the suggested curriculum would be distributed to all medical schools for consideration. Such a curriculum could also be modified to make it relevant to other health care providers, including physician assistants, nurses, and nurse practitioners.

Every medical student will one day be a physician who could face a disaster situation. Accordingly, medical schools should embrace further disaster education at the medical student level. The natural and man-made events in the recent past have taught us that preparation is the key to a successful outcome. The community as a whole depends on physicians and other health care professionals to be ready to provide the highest caliber health care, regardless of the situation.

\section{Author Contributions}

Authors Parrillo, Christensen, Teitelbaum, and Glassman provided substantial contributions to concept and design, acquisition of data, or analysis and interpretation of data. These authors also drafted the article or revised it critically for important intellectual content; these authors gave final approval of the version of the article to be published.

7. Subbarao I, Lyznicki JA, Hsu EB, et al. A consensus-based educational framework and competency set for the discipline of disaster medicine and public health preparedness. Dis Med Public Health Prep. 2008;2(1):57-68.

8. Markenson D, DiMaggio C, Redlener I. Preparing health professions students for terrorism, disaster, and public health emergencies: core competencies. Acad Med. 2005;80(6):517-526.

9. Kaiser HE, Barnett DJ, Hsu EB, et al. Perspectives of future physicians on disaster medicine and public health preparedness: challenges of building a capable and sustainable auxiliary medical workforce. Dis Med Public Health Prep. 2009;3(4):210-216.

10. Greenberg R. Record Number of Students Enroll in Medical School, AAMC Data Show, AAMC Reporter: November/December 2014. https://www.aamc.org/ newsroom/reporter/ novemberdecember2014/419300/record-number.html. Accessed March 15, 2016.

11. DeMiglio P. AACOM Releases New Osteopathic Medical College Student Enrollment Data. http://www.aacom.org/news-and-events/press-releases-and-statements/press-releasedetails/2015/10/21/2015-enrollment-data. Accessed March 15, 2016. 